\title{
Albaflavenol B, a new sesquiterpene isolated from the terrestrial actinomycete, Streptomyces sp.
}

\author{
Ritesh Raju ${ }^{1}$, Oleksandr Gromyko², Viktor Fedorenko ${ }^{2}$, Andriy Luzketskyy ${ }^{2}$ and Rolf Müller ${ }^{1}$ \\ The Journal of Antibiotics (2015) 68, 286-288; doi:10.1038/ja.2014.138; published online 1 October 2014
}

Secondary metabolites from plant-associated actinomycetes are increasingly attracting attention, with the recent identification of new secondary metabolites, juniperolide $\mathrm{A},{ }^{1}$ lorneic acids, ${ }^{2}$ leopolic acid $^{3}$ and oleaceran. ${ }^{4}$ As part of our ongoing campaign to focus natural products discovery on this source, we have isolated and characterized a new sequiterpene, alblaflavenol B (1).

The strain (Lv-4-26), identified as belonging to the genus Streptomyces, was isolated from the soil collected from the root zone of the plant Phyllostachys viridiglaucescens. The strain was later cultivated in $\mathrm{M}$ medium consisting of (starch $1 \%$, yeast extract $0.4 \%$ and peptone $0.2 \%$ ) for 8 days at $30{ }^{\circ} \mathrm{C}$ in five 5 liters Erlenmeyer flask containing 1.4 liters of medium each. The whole broth was then later extracted with ethyl acetate $(6 \mathrm{l})$ to give a crude extract of $110.5 \mathrm{mg}$. The EtOAc extract was then sequentially fractionated between $20 \mathrm{ml}$ of hexane, $\mathrm{CH}_{2} \mathrm{Cl}_{2}$ and $\mathrm{MeOH}$ to afford 40.6, 55.7 and $5.5 \mathrm{mg}$ fractions, respectively. The $\mathrm{CH}_{2} \mathrm{Cl}_{2}$ fraction was subsequently purified by semipreparative reverse-phase HPLC to yield the sesquiterpene, $1\left(t_{\mathrm{R}}=14.5\right.$ min; $0.7 \mathrm{mg}$ ). The structure of albalfavenol B was elucidated through detailed spectroscopic analysis, while the absolute configuration was assigned by comparison to its known derivatives, albaflavenol $(\mathbf{2} \mathbf{a} / \mathbf{2} \mathbf{b})$ and albaflavenone (3).

HRESI (+)MS analysis of $\mathbf{1}$ (Table 1) revealed a pseudomolecular ion $\left([\mathrm{M}+\mathrm{Na}]^{+}\right)$indicative of a molecular formula $\left(\mathrm{C}_{15} \mathrm{H}_{24} \mathrm{O}_{2}\right)$ requiring four double bond equivalents. The NMR (DMSO- $\left.d_{6}\right)$ data

Table 1 Physico-chemical properties of 1

\begin{tabular}{ll}
\hline & \multicolumn{1}{c}{1} \\
\hline Appearance & Colorless oil \\
HR-ESI-MS $(\mathrm{m} / \mathrm{z})$ & \\
Found & $259.1677[\mathrm{M}+\mathrm{Na}]^{+}$ \\
Calcd & $259.1669\left(\mathrm{C}_{15} \mathrm{H}_{24} \mathrm{O}_{2} \mathrm{Na}\right)$ \\
{$[\alpha]_{D}(\mathrm{MeOH})$} & $(+) 24^{\circ}$ \\
UV $\lambda_{\max } \mathrm{nm}(\log \varepsilon)(\mathrm{MeOH})$ & $220(4.40)$ \\
\hline
\end{tabular}

(Table 2) (Supplementary Figures S1-S4) revealed two $\mathrm{sp}^{2}$ carbon resonances $\left(\delta_{\mathrm{C}} 137.1\right.$ and 150.4$)$ requiring that 1 be tricyclic. Analysis of the COSY correlations led to the generation of the first isolated spin system, which began with a secondary methyl $\mathrm{H}_{3}-12\left(\delta_{\mathrm{H}} 0.89\right)$ linked to a methine $\mathrm{H}-2\left(\delta_{\mathrm{H}} 1.68\right)$ and then to a methylene $\mathrm{H}_{2}-3\left(\delta_{\mathrm{H}} 2.13\right.$, $1.21)$ and terminating at the oxymethine $\mathrm{H}-4\left(\delta_{\mathrm{H}} 4.56\right)$. The second spin system consisted of two methylenes $\mathrm{H}_{2}-9$ and $\mathrm{H}_{2}-10$ extending futher to the methine $\mathrm{H}-8\left(\delta_{\mathrm{H}} 1.77\right)$ and terminating at the methylene $\mathrm{H}_{2}-11\left(\delta_{\mathrm{H}} 1.44,1.32\right)$. The key HMBCs from $\mathrm{H}_{3}-12$ to $\mathrm{C}-1$ and $\mathrm{H}-4$ to $\mathrm{C}-1, \mathrm{C}-4$ and $\mathrm{C}-5$ led to the generation of a substituted cyclopentane ring ( $\mathrm{C}-1$ to $\mathrm{C}-5)$. A second set of HMBCs revealed a second

Table 2 NMR (500 MHz, DMSO-d6) data for albaflavenol B (1)

\begin{tabular}{|c|c|c|c|c|}
\hline Pos & $\delta_{H}$, mult $(J$ in $\mathrm{Hz})$ & $\delta_{C}{ }^{a}$ & $\cos Y$ & $H M B C$ \\
\hline 1 & & 52.5 & & \\
\hline 2 & $1.68, \mathrm{~m}$ & 35.6 & 3,12 & 1,12 \\
\hline За & $2.13, \mathrm{~m}$ & 42.9 & 2,4 & $1,2,4,5$ \\
\hline $3 b$ & $1.21, \mathrm{~m}$ & & & \\
\hline 4 & $4.56, \mathrm{t}(7.8)$ & 70.2 & 3 & $1,5,6$ \\
\hline 5 & & 150.4 & & \\
\hline 6 & & 137.1 & & \\
\hline 7 & & 40.4 & & \\
\hline 8 & $1.77, \mathrm{~m}$ & 46.9 & $9 \mathrm{a} / \mathrm{b}, 11 \mathrm{a} / \mathrm{b}$ & 1,6 \\
\hline $9 a$ & $1.73, \mathrm{~m}$ & 24.4 & $8,10 a$ & \\
\hline $9 b$ & $1.58, \mathrm{~m}$ & & $8,10 a$ & \\
\hline $10 a$ & $1.42, \mathrm{~m}$ & 29.6 & $9 a$ & 1 \\
\hline $10 b$ & $1.23, \mathrm{~m}$ & & & \\
\hline $11 \mathrm{a}$ & $1.44, \mathrm{~m}$ & 36.8 & 8 & 1 \\
\hline $11 b$ & $1.32, \mathrm{~m}$ & & & 8 \\
\hline 12 & $0.89, \mathrm{~d}(6.8)$ & 14.1 & 2 & $1,2,3$ \\
\hline 13 & 3.94, dd $(13.5,11.6)$ & 57.6 & & $5,6,7$ \\
\hline 14 & $0.99, \mathrm{~s}$ & 29.3 & & $6,7,8,15$ \\
\hline 15 & $1.05, \mathrm{~s}$ & 24.9 & & $6,7,8,14$ \\
\hline
\end{tabular}

${ }^{13} \mathrm{C}$ NMR resonances obtained from $2 \mathrm{D} \mathrm{HSQC}$ and HMBC experiments.

${ }^{1}$ German Centre for Infection Research Association, Braunshweig, Germany and ${ }^{2}$ Department of Genetics and Biotechnology of Ivan Franko National University of L'viv, L'viv, Ukraine

Correspondence: Professor R Müller, Department of Microbial Natural Products, Helmholtz Institute for Pharmaceutical Research Saarland, Universitat des Saarlandes Universitats Campus, Gebaude C2 3, Saarbruecken 66041, Germany.

Email: rom@mx.uni-saarland.de

Received 29 April 2014; revised 12 July 2014; accepted 1 August 2014; published online 1 October 2014 
cyclopentane unit fused at position C-1. Finally, the tertiary methyls $\mathrm{H}_{3}-14\left(\delta_{\mathrm{H}} 0.99\right)$ and $\mathrm{H}_{3}-15\left(\delta_{\mathrm{H}} 1.05\right)$ showed correlations to C-6, C-7 and $\mathrm{C}-8$, while the methylene $\mathrm{H}_{2}-13$ (3.94) showed correlations to C-5, C-6 and C-7, leading to the construction of the cyclohexene ring fused alongside the two cyclopentane ring system (Figure 1). The overall planar structure was analogous to albaflavenone $(3),{ }^{5}$ a sesquiterpene ketone with the two differences being the reduction of the ketone into a secondary alcohol and the presence of a hydroxyl methylene as opposed to a olefinic methyl (Figure 2). Albaflavenols ${ }^{6}$ $(\mathbf{2} \mathbf{a} / \mathbf{2} \mathbf{b})$ were isolated as a mixture of epimeric alcohols in a biosynthetic-related study, where the absolute configuration of the hydroxyls was assigned as $4 R$ and $4 S$ based on the use of Hyperchem 7.5 for predictions. We observed a coupling of $7.8 \mathrm{~Hz}$ for $\mathrm{H}-4$ as a triplet in our experimental data, which was in agreement with the $4 R$ configuration (Figure 2). The remaining absolute stereochemistry is drawn as that for albaflavenone based on a comparison of the optical

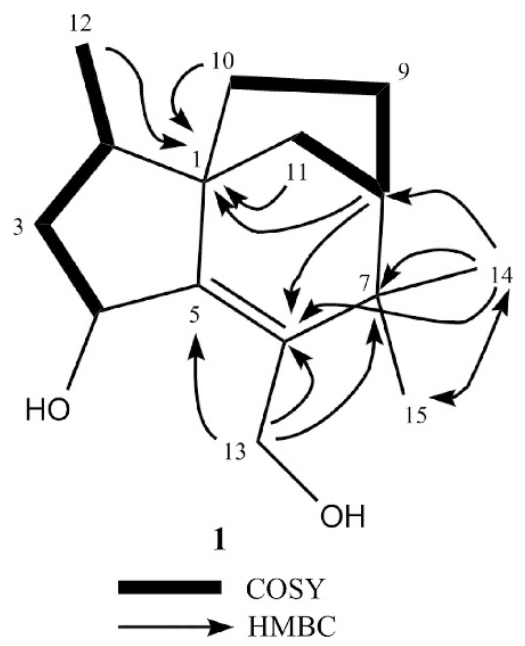

Figure 1 Key 2D NMR correlations for 1 . rotation and on biosynthetic grounds. Recently, as part of a characterization of the silent sesquiterpenoid biosynthetic pathway in Streptomyces avermitilis led to the discovery of $4 \beta, 5 \beta$-epoxy-2epi-zizaan-6 $\beta$-ol (4) (Figure 2), which was most likely to be formed by oxidation of $(4 S)$-albaflavenol. ${ }^{7}$ In summary, we have isolated a new derivative of albaflavenone, albaflavenol B (1) the first of the albaflavenols to be isolated as a pure substance rather than an epimeric mixture of alcohols. Owing to low yields and very low reproducibility of the metabolite from the strain, we failed to obtain a biological profile of this metabolite.

\section{EXPERIMENTAL PROCEDURE}

NMR spectra were obtained on a Bruker Ascend $500 \mathrm{MHz}$ spectrometer equipped with a cryoprobe system (Bruker Biospin GmbH, Waldbronn, Germany), in the solvents indicated and referenced to residual ${ }^{1} \mathrm{H}$ signals in deuterated solvents. ESI-MS were acquired using an Agilent 1100 Series separations module equipped with an Agilent 1100 Series LC/MSD mass detector in both positive and negative ion modes under the following conditions: Zorbax $\mathrm{C}_{8}$ column, $150 \times 4.6 \mathrm{~mm}$, eluting with $0.4 \mathrm{ml} \mathrm{min}^{-1} 95 \%$ $\mathrm{H}_{2} \mathrm{O} / \mathrm{MeCN}$ to $5 \% \mathrm{H}_{2} \mathrm{O} / \mathrm{MeCN}$ (with isocratic $0.01 \%$ trifluoroacetic acid (TFA)) over $22 \mathrm{~min}$, then held for $5 \mathrm{~min}$. HRMS was carried out using an UltiMate 3000 rapid separation liquid chromatography system (Dionex RSLC, Crawford Scientific, Lanarkshire, UK) coupled to an UHR-TOF mass spectrometer (Bruker Daltonik MaXis, Bremen, Germany) operating in the positive ESI mode.

Sampling was performed in the Nikitsky Botanical Garden in the south part of Crimea (Ukraine). The soil was collected $(1 \mathrm{~g})$ from the root zone of the plant $P$. viridiglaucescens and resuspended in sterile water $(10 \mathrm{ml})$. Serial dilutions of the soil suspension were prepared in sterile water and inoculated onto the oatmeal agar (oatmeal $-40 \mathrm{gl}^{-1}$, agar $-15 \mathrm{gl}^{-1}, \mathrm{pH} 7.5$ ). The plates were then later incubated for 20 days at $28^{\circ} \mathrm{C}$. Individual colonies were transferred onto new oatmeal agar plates for further analysis and maintenance. Based on 16s rDNA sequence analysis, strain Lv4-26 was identified to belong to the genus Streptomyces. The strain Streptomyces sp., Lv-4-26 is deposited in the microorganism collection of Ivan Franko Lviv National University.

\section{ACKNOWLEDGEMENTS}

Research in RM's laboratory was supported by grants from the BMBF and the DFG.
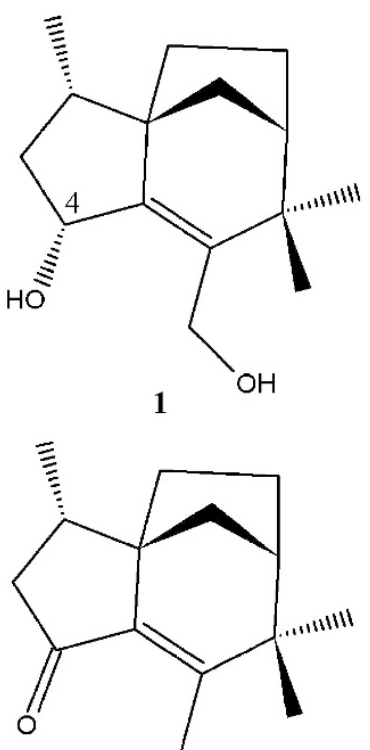

3

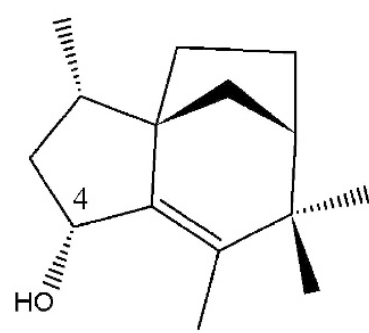

2a

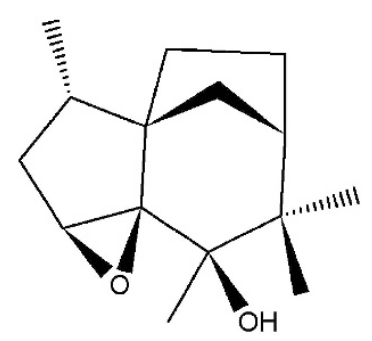

4

Figure 2 Structures of compounds $1-4$. 
1 Raju, R., Gromyko, O., Fedorenko, V., Luzhetskyy, A., Plaza, A., Müller, R. Juniperolide, A. A new polyketide isolated from a terrestrial actinomycete, Streptomyces sp. Org. Lett. 14, 5860-5863 (2012).

2 Raju, R., Gromyko, O., Fedorenko, V., Luzhetskyy, A., Müller, R. Lorneic acids $\mathrm{C}$ and $\mathrm{D}$, new trialkyl-substituted aromatic acids isolated from a terrestrial Streptomyces sp. J. Antibiot. 66, 347-349 (2013)

3 Raju, R., Gromyko, O., Fedorenko, V., Luzhetskyy, A., Plaza, A., Müller, R. Leopolic acid A, isolated from a terrestrial actinomycete, Streptomyces sp. Tetrahedron Lett. 53 6300-6301 (2012)

4 Raju, R., Gromyko, O., Fedorenko, V., Luzhetskyy, A., Plaza, A., Müller, R. Oleaceran: a novel spiro[isobenzofuran-1,2'-naptho[1,8-bc]furan] isolated from a terrestria Streptomyces sp. Org. Lett. 15, 3487-3489 (2013).

5 Gürtler, H., Pedersen, R. Albaflavenone, a sesquiterpene ketone with a zizaene skeleton produced by a streptomycete with a new rope morphology. J. Antibiot. 47, 434-439 (1994).

6 Zhao, B. et al. Biosynthesis of the sesquiterpene antibiotic albaflavenone in Streptomyces coelicolor A3(2). J. Biol. Chem. 283, 8183-8189 (2008).

7 Takamatsu, S. et al. Characterization of a silent sesuiterpenoid biosynthetic pathway in Streptomyces avermitilis controlling epi-isozizaene albaflavenone biosynthesis and isolation of a new oxidized epi-isozizaene metabolite. Microbial Biotechnol. 4, 184-191 (2011).

Supplementary Information accompanies the paper on The Journal of Antibiotics website (http://www.nature.com/ja) 